\title{
The tumour-stromal interaction between intratumoral c-Met and stromal hepatocyte growth factor associated with tumour growth and prognosis in non-small-cell lung cancer patients
}

\author{
D Masuya', C Huang*,', D Liu', T Nakashima', K Kameyama', R Haba', M Ueno ${ }^{3}$ and H Yokomise' \\ 'Second Department of Surgery, Kagawa Medical University, I 750-I Miki-cho, Kita-gun, Kagawa 761 -0793, Japan; '2Department of Pathology, Kagawa \\ Medical University, Kagawa, Japan; ${ }^{3}$ Department of Pathology and Host Defense, Kagawa Medical University, Kagawa, Japan
}

Immunohistochemical analyses of the effects of hepatocyte growth factor (HGF) and c-Met expression on tumour growth and angiogenesis were performed on 88 patients with non-small-cell lung cancers (NSCLCs). In all, 22 carcinomas (25.0\%) were intratumoral HGF-positive, 14 carcinomas ( I .9\%) were stromal HGF-positive, and 36 carcinomas (40.9\%) were intratumoral c-Metpositive. None of the carcinomas were stromal c-Met-positive. Examination of tumour growth revealed that the frequency of tumours with a high Ki-67 index was significantly greater for stromal HGF-positive tumours than for stromal HGF-negative tumours $(P=0.0197)$. The frequency of tumours with a high Ki-67 index was also significantly greater for intratumoral c-Met-positive tumours than for intratumoral c-Met-negative tumours $(P=0.030 \mathrm{I})$. However, there was no significant difference in tumour vascularity with relation to intratumoral HGF status, stromal HGF status, and intratumoral c-Met status. The survival rate of patients with intratumoral c-Met-positive tumours was significantly lower than for patients with c-Met-negative tumours $(P=0.0095)$. Furthermore, the survival rate of patients with both intratumoral c-Met-positive and stromal HGF-positive tumours was significantly lower than for patients with either positive tumours, and that of patients with both negative tumours $(P=0.0183$ and $P=0.00$ II, respectively). A univariate analysis revealed that intratumoral c-Met expression was a significant prognostic factor of NSCLC patients (relative risk $=2.642$, $P=0.0029)$. The present study demonstrates that tumour-stromal interaction between tumour cell-derived c-Met and stromal cellderived HGF affects tumour growth and the prognosis of NSCLC patients.

British Journal of Cancer (2004) 90, I555- 1562. doi:I0.1038/sj.bjc.660 I7I 8 www.bjcancer.com

Published online 23 March 2004

(c) 2004 Cancer Research UK

Keywords: HGF; c-Met; Ki-67; immunohistochemistry; lung cancer

Non-small-cell lung cancer (NSCLC) is one of the most common human malignancies with a poor prognosis. It is widely accepted that malignant tumours are caused by the accumulation of genetic alterations, which reflect the biological behaviour of tumours, such as aggressive cell proliferation as well as invasive and metastatic potential (Cordon-Cardo, 1995). Therefore, it is considered important to understand the biological behaviour of NSCLCs, to improve the clinical outcome of NSCLC patients.

Tumour-stromal interaction is an essential part of malignant progression in vivo (Chung, 1995). During tumour development, stromal fibroblasts produce an extracellular matrix that is used as an anchorage by tumour cells. In addition, the extracellular matrix also functions as a reservoir of growth factors derived from tumour or stromal cells. Various growth factors and their receptors, including hepatocyte growth factor (HGF)/c-Met, epithelial growth factor (EGF)/EGF-R, and the vascular endothelial growth factor (VEGF) family/VEGF-Rs, are reported to be involved

*Correspondence: Dr C Huang, Second Department of Surgery, Kagawa Medical University, I750-I Miki-cho, Kita-gun, Kagawa 76I-0793, Japan. E-mail: chuang@kms.ac.jp

Received 30 October 2003; accepted 19 January 2004; published online 23 March 2004 in tumour-stromal interactions (Nakamura et al, 1997; Turkeri et al, 1998; Kajita et al, 2001).

Among these growth factors and their receptors, the HGF/c-Met pathway has multiple biological functions, such as cell proliferation (Montesano et al, 1991), motility (Weidner et al, 1990), angiogenesis (Bussolino et al, 1992), and morphogenesis (Brinkmann et al, 1995). Many human cancers exhibit overexpression of HGF and/or c-Met (Olivero et al, 1996; Kurimoto et al, 1998; Edakuni et al, 2001), and several clinical studies revealed that overexpression of HGF and/or c-Met is associated with the prognosis of NSCLC patients (Ichimura et al, 1996; Takanami et al, 1996; Siegfried et al, 1997). However, the mechanisms of their biological behavior in NSCLCs are not fully understood in part because they have multiple functions.

To clarify the role of $\mathrm{HGF} / \mathrm{c}-$ Met in NSCLCs, we undertook a clinical study of HGF and c-Met expression in relation to tumour growth and vascularity. We evaluated their expression using immunohistochemistry to differentiate tumour cell-derived expression from stromal cell-derived expression. In addition, we studied their effects on cell proliferation rate using the Ki-67 labeling index (Gerde et al, 1984; Scagliotti et al, 1993) and their ability to promote tumour angiogenesis was evaluated by intratumoral microvessel density (IMD) using CD34 staining (Matsuyama et al, 1998). 


\section{MATERIALS AND METHODS}

\section{Clinical characteristics of patients}

NSCLC patients who underwent surgery at the Second Department of Surgery, Kagawa Medical University, from January 1993 to March 2001, were examined. Tumour-node-metastasis (TNM) staging designations were assigned according to the postsurgical pathological international staging system (Mountain, 1997). Since Stage IV-lung cancer involves several ill-defined factors and has distant metastases, patients with these signs were excluded from the study. Patients with two or more types of cancers and patients, who died of causes other than NSCLC, were also excluded. In total, 88 NSCLC patients were investigated. Among them were 46 patients with adenocarcinoma, 29 patients with squamous cell carcinoma, and 13 patients with large-cell carcinoma. Patients' clinical records and histopathological diagnoses were fully documented. This report includes follow-up data until May 27, 2003. The mean follow-up period for all patients was $49.8 \pm 36.1$ months.

\section{Immunohistochemical staining of HGF, c-Met, Ki-67, and CD34}

We used a rabbit polyclonal antibody against HGF (SC-7949, Santa Cruz Biotechnology Inc., Santa Cruz, CA, USA) at $1: 100$ dilution, a rabbit polyclonal antibody against c-Met (SC-10, Santa Cruz Biotechnology Inc., Santa Cruz, CA, USA) at 1:100 dilution, a mouse monoclonal antibody against Ki-67 (MIB-1, DAKO, Glostrup, Denmark) at 1:40 dilution, and a mouse monoclonal antibody against CD34 (NU-4A1, Nichirei Corporation, Tokyo, Japan) at $1: 10$ dilution.

Formalin-fixed paraffin-embedded tissue was cut into $4-\mu \mathrm{m}-$ thick sections and mounted on poly-L-lysine-coated slides. Sections were then deparaffinized and rehydrated, heated in a microwave for $10 \mathrm{~min}$ in a $10-\mu \mathrm{moll}^{-1}$ citrate buffer solution at $\mathrm{pH}$ 6.0 , and cooled to room temperature for $20 \mathrm{~min}$. After quenching endogenous peroxidase activity with $0.3 \% \mathrm{H}_{2} \mathrm{O}_{2}$ (in absolute methanol) for $30 \mathrm{~min}$, the sections were treated for $2 \mathrm{~h}$ at room temperature with $5 \%$ bovine serum albumin to block nonspecific staining. The sections were subsequently incubated overnight with primary specific antibodies against HGF, c-Met, Ki-67, and CD34, respectively. The slides were then incubated for $1 \mathrm{~h}$ with biotinylated anti-rabbit IgG (Vector Laboratories Inc., Burlingame, CA, USA) against HGF and c-Met, and biotinylated anti-mouse IgG (Vector Laboratories Inc., Burlingame, CA, USA) against Ki-67 and CD34. The sections were incubated with the avidin-biotinperoxidase complex (Vector Laboratories Inc.) for $1 \mathrm{~h}$, and antibody binding was visualized with $3,3^{\prime}$-diaminobenzidine tetrahydrochloride. As a final step, the sections were counterstained with Mayer's haematoxylin. Sections of resected lung tumours known to express HGF and c-Met were used as positive controls for immunostaining, and sections incubated with normal rabbit IgG served as negative reaction controls for staining of HGF and c-Met.

All immunostained sections were reviewed by two pathologists (RH and MU) who had no knowledge of the patients' clinical status. Cases with discrepancies were jointly reevaluated and a consensus was reached. In cases with multiple areas of low intensity that occurred during evaluation of immunostaining of HGF and c-Met, five areas were selected at random and scored. Also, one random field was selected in sections where all staining appeared intense. At least 200 tumour cells were scored per $\times 40$ field. The sample was classified as intratumoral HGF-positive when $\geqslant 50 \%$ of the tumour cells in a given specimen were positively stained for HGF, and it was classified as intratumoral HGFnegative when $<50 \%$ of the cells were stained. In addition, the sample was classified as stromal HGF-positive when $\geqslant 50 \%$ of the stromal cells of tumours in a given specimen were positively stained for HGF, and it was classified as stromal HGF-negative when $<50 \%$ of the stromal cells were stained.

Since a homogeneous cytoplasmic staining pattern appeared in c-Met-stained tumour cells, c-Met staining was scored by staining intensity as reported previously (Jin et al, 1997; Ramirez et al, 2000). Staining intensity was classified as grade 0 (no staining), grade 1 (weak staining), grade 2 (moderately strong staining), grade 3 (very strong staining), or grade 4 (extremely strong staining). The sample was classified as intratumoral c-Met-positive when the intensity of c-Met-stained tumour cells in a given specimen was greater than grade 1 . All other samples of c-Metstained tumour cells were classified as intratumoral c-Metnegative.

The rate of tumour proliferation was evaluated by the percentage of carcinoma cells that stained positive for Ki-67 in a given specimen scored using the $\mathrm{Ki}-67$ proliferation index. Tumours with a Ki-67 proliferation index $\geqslant 25 \%$ were classified as high Ki-67, while tumours with $<25 \%$ were classified as low Ki67. For microvessel quantification, the three most vascularised areas detected by CD34 immunostaining were initially selected under $\times 40$ field, and $\times 200$ field $\left(0.785 \mathrm{~mm}^{2}\right.$ per field $)$, and microvessels were counted in each of these areas. The average count for three $\times 200$ fields was recorded as the IMD. Tumours with IMD $\geqslant 90$ were classified as hypervascular, while tumours with IMD $<90$ were classified as hypovascular (Masuya et al, 2001).

\section{Statistical analysis}

The overall cancer-specific survival was defined from the date of operation to the date of cancer-related death. Statistical significances in the expression of HGF, c-Met, Ki-67, and IMD in relation to several clinical and pathologic parameters were assessed using a $t$-test and $\chi^{2}$ test. The Kaplan-Meier method was used to estimate the probability of overall survival as a function of time, and survival periods were compared using a log-rank test. Analysis using the Cox regression model was performed to study the effects of different variables on survival rate. All $P$-values were based on two-tailed statistical analysis, and $P$-values $<0.05$ were taken to indicate the statistical significance.

\section{RESULTS}

\section{Hepatocyte growth factor expression in NSCLCs}

Hepatocyte growth factor staining of tumour or stromal cells appeared in the form of a heterogeneous cytoplasmic staining pattern. Among the 88 carcinomas examined for HGF expression in tumour cells, 22 carcinomas $(25.0 \%)$ were intratumoral HGFpositive, and 66 carcinomas $(75.0 \%)$ were intratumoral HGFnegative (Table 1 and Figure $1 \mathrm{~A})$. There was no significant difference in intratumoral HGF expression according to tumour histology, tumour status, nodal status, and tumour differentiation. With regard to HGF expression in the stromal cells of tumours, 14 carcinomas (15.9\%) were stromal HGF-positive and 74 carcinomas (84.1\%) were stromal HGF-negative (Table 1 and Figure 1B,C). There was also no significant difference in stromal HGF expression according to tumour histology, tumour status, nodal status, and tumour differentiation. In addition, there was no correlation between the percentage of HGF-positive tumour cells and HGFpositive stromal cells in each NSCLC $(r=0.066, P=0.5431)$.

\section{c-Met expression in NSCLCs}

c-Met-stained tumour cells showed a homogeneous cytoplasmic staining pattern with variable intensity. In contrast, no carcinoma exhibited positive c-Met staining in stromal cells. Of the 88 
Table I Distribution of 88 non-small-cell lung cancer patients according to HGF and c-Met status

\begin{tabular}{|c|c|c|c|c|c|c|c|c|c|c|}
\hline \multirow[b]{2}{*}{ Variables } & \multirow[b]{2}{*}{$n$} & \multicolumn{3}{|c|}{ Intratumoral HGF } & \multicolumn{3}{|c|}{ Stromal HGF } & \multicolumn{3}{|c|}{ Intratumoral c-Met } \\
\hline & & Positive & Negative & $P$-value & Positive & Negative & $P$-value & Positive & Negative & $P$-value \\
\hline \multicolumn{11}{|l|}{ Tumor status } \\
\hline $\mathrm{TI}$ & 35 & | | & 24 & 0.2577 & 7 & 28 & 0.3939 & 9 & 26 & 0.0185 \\
\hline $\mathrm{T} 2, \mathrm{~T} 3, \mathrm{~T} 4$ & 53 & 11 & 42 & & 7 & 46 & & 27 & 26 & \\
\hline \multicolumn{11}{|l|}{ Nodal status } \\
\hline No & 56 & 17 & 39 & 0.1247 & 10 & 46 & 0.5086 & 21 & 35 & 0.3895 \\
\hline $\mathrm{NI}, \mathrm{N} 2, \mathrm{~N} 3$ & 32 & 5 & 27 & & 4 & 28 & & 15 & 17 & \\
\hline \multicolumn{11}{|l|}{ Pathological stage } \\
\hline Stage I & 46 & 15 & 31 & 0.0756 & 9 & 37 & 0.7416 & 14 & 32 & 0.0169 \\
\hline Stage II & 10 & 1 & 9 & & I & 9 & & 2 & 8 & \\
\hline Stage IIIA & 12 & 0 & 12 & & 2 & 10 & & 8 & 4 & \\
\hline Stage IIIB & 20 & 6 & 14 & & 2 & 18 & & 12 & 8 & \\
\hline \multicolumn{11}{|l|}{ Differentiation } \\
\hline Well & 30 & 8 & 22 & 0.0717 & 2 & 28 & 0.1606 & 10 & 20 & 0.2299 \\
\hline Moderately & 30 & | | & 19 & & 5 & 25 & & 16 & 14 & \\
\hline Poorly & 28 & 3 & 25 & & 7 & 21 & & 10 & 18 & \\
\hline \multicolumn{11}{|l|}{ Histology } \\
\hline Adenocarcinoma & 46 & 16 & 30 & 0.0687 & 5 & 41 & 0.0520 & 22 & 24 & 0.1099 \\
\hline Squamous cell carcinoma & 29 & 5 & 24 & & 4 & 25 & & 12 & 17 & \\
\hline Large-cell carcinoma & 13 & I & 12 & & 5 & 8 & & 2 & | | & \\
\hline Total number of patients & 88 & 22 & 66 & & 14 & 74 & & 36 & 52 & \\
\hline
\end{tabular}

HGF = hepatocyte growth factor.

carcinomas studied, 36 carcinomas $(40.9 \%)$ were intratumoral cMet-positive, and 52 carcinomas (59.1\%) were intratumoral c-Metnegative (Table 1 and Figure $1 \mathrm{D}-\mathrm{G}$ ). There was no significant difference in intratumoral c-Met expression according to tumour histology, tumour differentiation, and nodal status. However, the frequency of intratumoral c-Met-positive tumours was significantly higher for T2-4 tumours than for T1 tumours (50.9 vs $25.7 \%, P=0.0185)$.

\section{Ki-67 proliferation index in NSCLCs}

The mean value of the Ki-67 proliferation index among the 88 NSCLCs studied was $44.2 \pm 31.0$. In all, 44 carcinomas $(50.0 \%)$ had a high Ki-67 index and 44 carcinomas (50.0\%) had a low Ki-67 index (Figure $1 \mathrm{H})$. Of the 46 adenocarcinomas, 16 tumours (34.8\%) had a high Ki-67 index and 22 tumours (75.9\%) of the 29 squamous cell carcinomas had a high Ki-67 index. Among the 13 large cell carcinomas, six tumours (46.2\%) had a high Ki-67 index. The frequency of tumours with a high Ki-67 index was significantly greater for squamous cell carcinomas than for adenocarcinomas $(P<0.001)$.

\section{Tumour vascularity in NSCLCs}

The mean IMD value in the 88 NSCLCs was $97.7 \pm 52.8$. In total, 45 carcinomas (51.1\%) were hypervascular and 43 carcinomas $(48.9 \%)$ were hypovascular. Of the 46 adenocarcinomas 31 tumours $(67.4 \%)$ were hypervascular, and eight tumours $(27.6 \%)$ among the 29 squamous cell carcinomas were hypervascular. Also, six tumours (46.2\%) of the 13 large-cell carcinomas were hypervascular. The frequency of hypervascular tumours was significantly higher for adenocarcinomas than for squamous cell carcinomas $(P<0.001)$.

\section{Ki-67 proliferation index in relation to HGF and c-Met status}

There was no difference in Ki-67 index between intratumoral HGFpositive tumours and intratumoral HGF-negative tumours $(44.7 \pm 30.8$ vs $42.5 \pm 32.4)$ with regard to intratumoral HGF expression. However, the $\mathrm{Ki}-67$ proliferation index was $59.9 \pm 24.5$ among stromal HGF-positive tumours, and $41.2 \pm 31.4$ among stromal HGF-negative tumours. The Ki-67 proliferation index was significantly greater in stromal HGF-positive tumours than in stromal HGF-negative tumours $(P=0.0386)$. Of the 14 stromal HGF-positive tumours, 11 tumours $(78.6 \%)$ had a high Ki67 index, and 33 tumours (44.6\%) among the 74 stromal HGFnegative tumours had a high Ki-67 index. The frequency of tumours with a high Ki-67 index was significantly greater for stromal HGF-positive tumours than for stromal HGF-negative tumours $(P=0.0197$, Figure $2 \mathrm{~A})$.

The Ki-67 proliferation index was $48.5 \pm 28.8$ among intratumoral c-Met-positive tumours, and $41.3 \pm 32.4$ among intratumoral c-Met-negative tumours. Of the 36 intratumoral c-Met-positive tumours, 23 tumours (63.9\%) had a high Ki-67 index, while 21 tumours $(40.4 \%)$ of the $52 \mathrm{c}$-Met-negative tumours had a high Ki-67 index. The frequency of tumours with a high Ki-67 index was significantly greater for intratumoral c-Met-positive tumours than for intratumoral $c$-Met-negative tumours $(P=0.0301$, Figure 2B).

There was no significant correlation between the percentage of HGF-positive stromal cells and the percentage of c-Met-positive tumour cells in each NSCLC $(r=0.030, P=0.7802)$. Therefore, the 88 NSCLCs examined were classified into three groups according to stromal HGF status and intratumoral c-Met status; one group in which six patients had tumours that exhibited both positive stromal HGF and intratumoral c-Met expression; a second group in which 38 patients had tumours which demonstrated either 

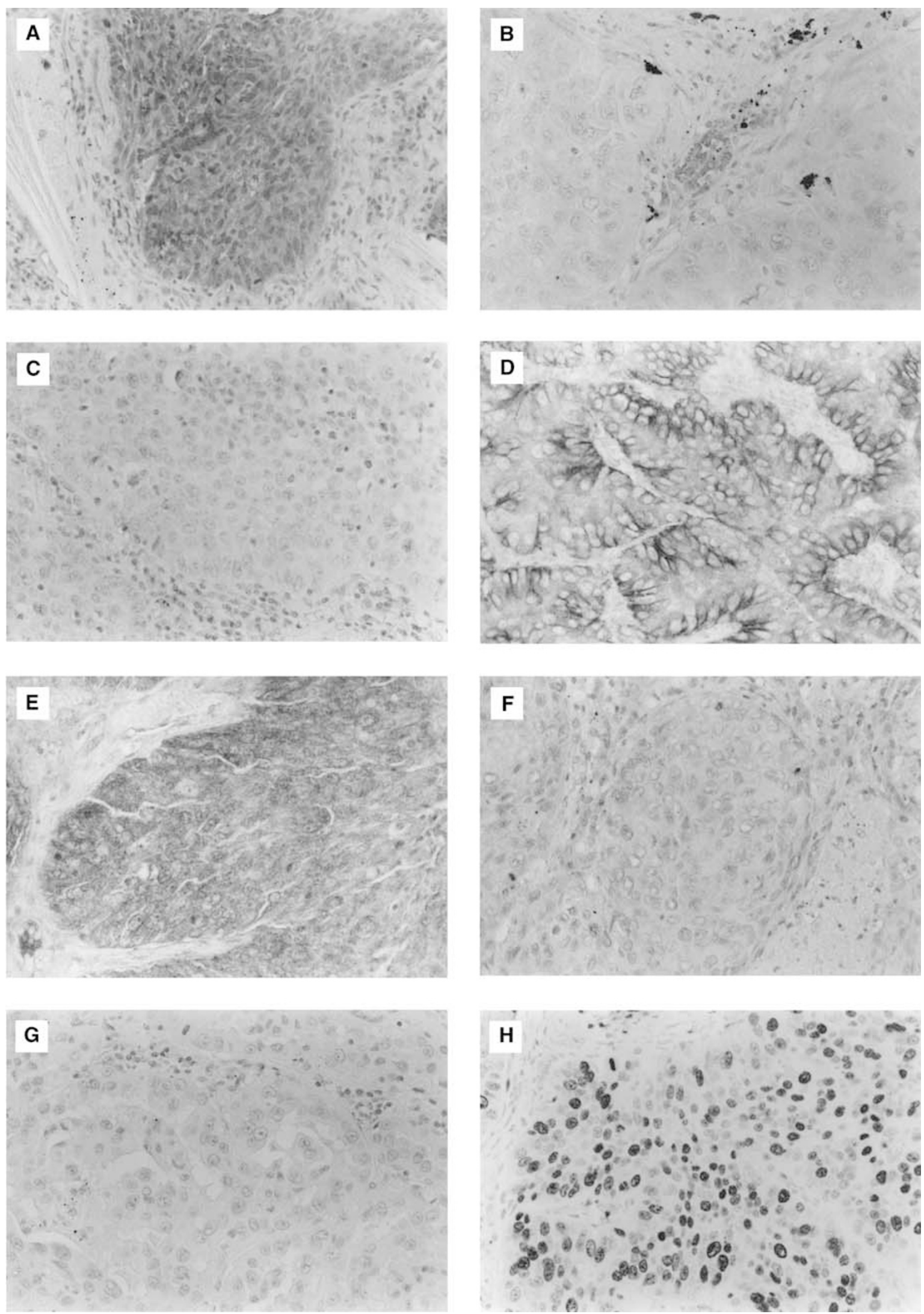

Figure I Immunohistochemical staining of human non-small-cell lung cancer tissues using the avidin-biotin-peroxidase complex procedure (original magnification, x 100). (A) An intratumoral HGF-positive squamous cell carcinoma. (B) A stromal HGF-positive squamous cell carcioma. (C) A stromal HGF-negative adenocarcinoma. (D) An intratumoral c-Met-positive adenocarcinoma. (E) An intratumoral c-Met-positive squamous cell carcinoma. (F) An intratumoral c-Met-negative squamous cell carcinoma. (G) An intratumoral c-Met-negative adenocarcinoma. (H) Ki-67 staining of an adenocarcinoma. 
A

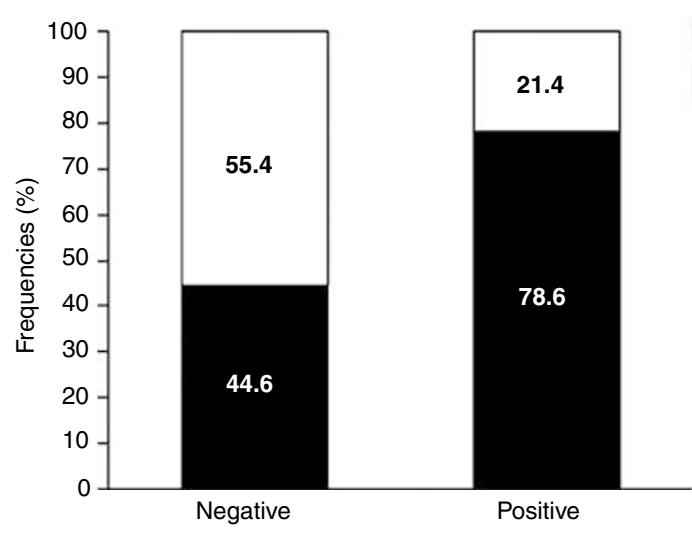

Stromal HGF status

\section{B}

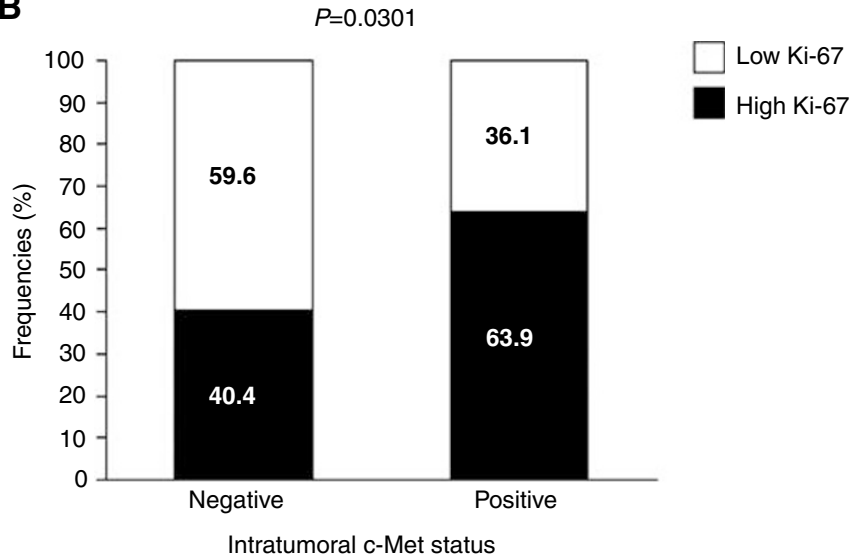

C

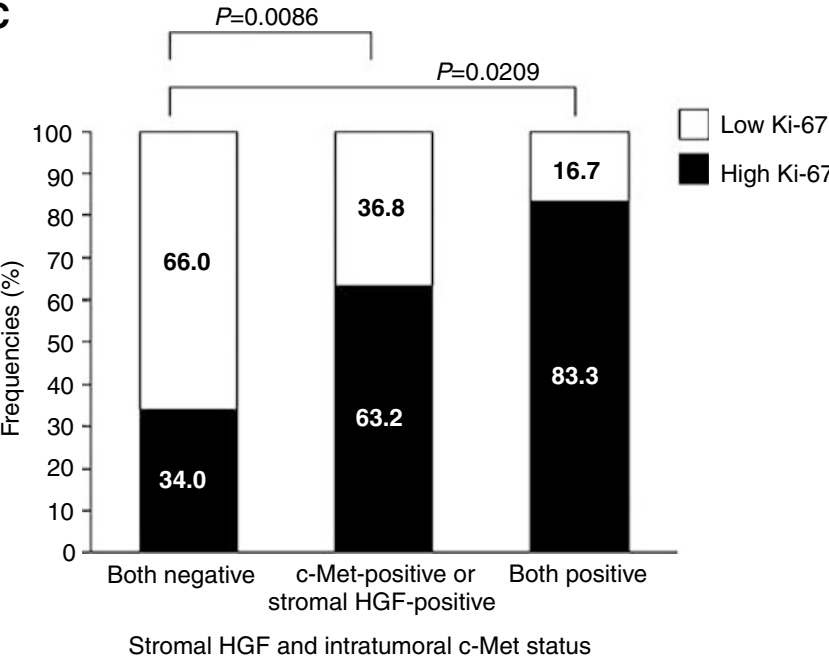

Figure 2 (A) Tumour proliferation rate in relation to stromal HGF status in NSCLCs. (B) Tumour proliferation rate in relation to intratumoral c-Met status in NSCLCs. (C) Tumour proliferation rate in relation to stromal HGF status and intratumoral c-Met status in NSCLCs.

positive stromal HGF or intratumoral c-Met expression; and a third group where 44 patients had tumours that showed negative expression for both HGF and c-Met. The frequency of tumours with a high $\mathrm{Ki}-67$ index was $83.3 \%$ in the first group, $63.2 \%$ in the second group, and $34.0 \%$ in the third group. The frequency of high Ki-67 tumours in the third group was significantly lower than that for the other two groups $(P=0.0086$ and 0.0209 , respectively, Figure 2C).

\section{Tumour vascularity in relation to $\mathrm{HGF}$ and c-Met}

No significant difference was found in IMD between intratumoral HGF-positive and intratumoral HGF-negative tumours (103.2 \pm 41.4 vs $96.0 \pm 55.9)$. In addition, there was no significant difference in IMD between stromal HGF-positive and stromal HGF-negative tumours (106.6 \pm 60.2 vs 95.9 \pm 51.4$)$. Also, no significant difference was evident in IMD between intratumoral c-Met-positive and intratumoral c-Met-negative tumours $(103.4 \pm 58.9$ vs $89.3 \pm 41.4)$.

\section{Overall survival of NSCLC patients in relation to HGF and c-Met status}

The 5-year survival rates of the 88 NSCLC patients according to intratumoral HGF status, stromal HGF status, and c-Met status are shown in Table 2. There was no significant difference in survival among the patients in relation to intratumoral HGF status. In addition, there was also no significant difference with relation to stromal HGF status.

With respect to intratumoral c-Met status, however, the 5-year survival rate of patients with intratumoral c-Met-positive tumours was significantly lower than that for patients with intratumoral cMet-negative tumours (33.8 vs 63.2\%, $P=0.0095$, Figure 3A). Also, the 5-year survival rate for patients with $\mathrm{c}$-Met-positive adenocarcinomas was significantly lower than that for patients with cMet-negative adenocarcinomas (33.9 vs 65.9\%, $P=0.0399$, Figure 3B). Furthermore, the 5-year survival rate for patients with c-Met-positive tumours was significantly lower than that for patients with c-Met-negative tumours, especially in T2-4 tumours (21.0 vs $53.2 \%, P=0.0481$, Figure 3C). A univariate analysis using the Cox regression model demonstrated that intratumoral c-Met status was a significant factor for predicting the prognosis of NSCLC patients (relative risk $=2.642, P=0.0029$ ).

Since a correlation between the Ki- 67 proliferation index and both intratumoral c-Met and stromal HGF expression was demonstrated, the survival of NSCLC patients according to intratumoral c-Met and stromal HGF status was analysed (Figure 3D). The 5-year survival rate was $61.4 \%$ for patients with both negative tumours, $45.3 \%$ for patients with either type of positive tumours, and $0 \%$ for patients with both positive tumours. The 5-year survival rate for patients with both positive tumours was significantly lower than that for patients with either type of positive tumours, and that for patients with both negative tumours $(P=0.0183$ and 0.0011 , respectively)

\section{DISCUSSION}

Hepatocyte growth factor was discovered to be a mitogen for hepatocytes (Nakamura et al, 1989), and subsequently found to be identical to the scatter factor (SF), which destroys epithelial cell adhesion and promotes cell motility (Weidner et al, 1991). To date, HGF is known to be a multifunctional cytokine which induces cell proliferation (Montesano et al, 1991), motility (Weidner et al, 1990), angiogenesis (Bussolino et al, 1992), and morphogenesis (Brinkmann et al, 1995), in a wide variety of normal and neoplastic cells. In addition, its receptor is c-Met (Bottaro et al, 1991), a transmembrane tyrosine kinase receptor encoded by the protooncogene c-Met (Park et al, 1987).

Overexpression of HGF and/or c-Met has been reported in various human cancers, including NSCLCs (Olivero et al, 1996) and breast cancers (Edakuni et al, 2001). Some tumour cell-derived factors, such as interleukin-1, basic fibroblast growth factor, and tumour necrosis factor- $\alpha$, are involved in the overexpression of 
Table 2 Five-year survival rate of 88 non-small-cell lung cancer patients according to HGF and c-Met status

\begin{tabular}{|c|c|c|c|c|c|c|c|c|c|}
\hline Variables & \multicolumn{3}{|c|}{ Intratumoral HGF } & \multicolumn{3}{|c|}{ Stromal HGF } & \multicolumn{3}{|c|}{ c-Met } \\
\hline $\mathrm{TI}$ & 80.8 & 69.1 & 0.2889 & 83.3 & 71.3 & 0.5920 & 72.9 & 72.5 & 0.7980 \\
\hline $\mathrm{T} 2, \mathrm{~T} 3, \mathrm{~T} 4$ & 40.4 & 35.8 & 0.6386 & 17.1 & 39.4 & 0.3220 & 21.0 & 53.2 & 0.0481 \\
\hline \multicolumn{10}{|l|}{ Nodal status } \\
\hline \multicolumn{10}{|l|}{ Pathological stage } \\
\hline Stage I & 78.3 & 75.7 & 0.6677 & 75.0 & 77.5 & 0.6903 & 68.9 & 80.0 & 0.4205 \\
\hline Stage \|I & 100.0 & 37.5 & 0.4440 & 0.0 & 50.0 & 0.5072 & 0.0 & 50.0 & 0.0941 \\
\hline Stage IIIA & 0.0 & 9.1 & $>0.9999$ & 0.0 & 11.1 & 0.1635 & 14.3 & 0.0 & 0.3456 \\
\hline Stage IIIB & 0.0 & 27.9 & 0.2223 & 0.0 & 20.7 & 0.4443 & 9.3 & 42.9 & 0.3808 \\
\hline \multicolumn{10}{|l|}{ Histology } \\
\hline Adenocarcinoma & 54.1 & 49.7 & 0.4936 & 75.0 & 49.6 & 0.5097 & 33.9 & 65.9 & 0.0399 \\
\hline Squamous cell carcinoma & 75.0 & 55.8 & 0.3609 & 0.0 & 67.2 & 0.1573 & 41.3 & 71.8 & 0.1464 \\
\hline Large-cell carcinoma & 100.0 & 33.3 & 0.3846 & 60.0 & 25.0 & 0.2568 & 0.0 & 45.5 & 0.0610 \\
\hline Total & 60.3 & 48.6 & 0.1735 & 50.7 & 52.2 & 0.8409 & 33.8 & 63.2 & 0.0095 \\
\hline
\end{tabular}

HGF = hepatocyte growth factor.

HGF in stromal fibroblasts (Tamura et al, 1993; Nakamura et al, 1997). In addition, one study revealed that cells transformed by the ras oncogene overexpressed c-Met (Webb et al, 1998). Thus, such growth factors produced in stromal cells interact with the receptors expressed on tumour cells (paracrine pattern) (Chung, 1995). In addition, malignant tumour cells also often produce growth factors and their associated receptors (autocrine pattern) (Edakuni et al, 2001). Therefore, the HGF/c-Met pathway plays an important role during tumour progression in a paracrine pattern and/or autocrine pattern.

Several clinical studies of the HGF/c-Met pathway in NSCLCs demonstrated that its expression was associated with a poor survival rate of NSCLC patients (Ichimura et al, 1996; Takanami et al, 1996; Siegfried et al, 1997). However, the precise mechanisms which control their behavior in NSCLCs are still not fully understood, partly because they have a variety of function and also because they originate from tumour or stromal cells. Therefore, we undertook this study using immunohistochemistry to investigate the relationship between the HGF/c-Met pathway and both tumour growth and angiogenesis.

This study initially revealed that HGF expression appeared independently in tumour cells and/or stromal cells. In contrast, cMet expression appeared only in tumour cells and not stromal cells, as reported by previous studies in human cancers (Ichimura et al, 1996; Kurimoto et al, 1998; Edakuni et al, 2001). Olivero et al, 1996 reported that c-Met staining was homogeneously distributed in a tumour mass, and that there was no staining of c-Met in normal lung tissue. However, HGF staining was detected in the cytoplasm of grouped cells scattered in tumour tissue, as reported previously (Olivero et al, 1996). These findings present here agreed well with these previous results. Therefore, we used different criteria to classify HGF and c-Met staining, respectively.

We then evaluated the rate of tumour proliferation using the Ki67 labeling index (Gerde et al, 1984; Scagliotti et al, 1993). Ki-67 antibody recognizes the nuclear antigen expressed during G1, S,
G2, and M phases of the cell cycle and not during the resting (G0) phase. The present study demonstrated significant association between the Ki-67 index and both stromal HGF and intratumoral c-Met expression. However, there was no correlation between the Ki-67 index and intratumoral HGF expression, as demonstrated by the low percentage of high $\mathrm{Ki}-67$ index tumours among stromal HGF and intratumoral c-Met-negative NSCLCs. In addition, the frequency of intratumoral c-Met-positive tumours was significantly higher for T2-4 tumours than for T1 tumours. These results indicated that the interaction between stromal cell-derived HGF and tumour cell-derived c-Met promote tumour cell proliferation in a paracrine manner. To our knowledge, this study is the first clinical report on NSCLCs that demonstrates a correlation between the HGF/c-Met pathway and tumour growth through tumourstromal interaction, as similarly reported for breast cancers (Edakuni et al, 2001).

The HGF/c-Met pathway is reported to be associated with angiogenesis (Bussolino et al, 1992), which is considered to be essential for tumour growth and metastasis (Folkman, 1990, 1995). Our previous studies revealed that tumour vascularity in NSCLCs is associated with intratumoral expression of VEGF-A (Masuya et al, 2001), interleukin-8 (Masuya et al, 2001), neuralcadherin (Nakashima et al, 2003), and that tumour vascularity is correlated with the survival rate of NSCLC patients (Nakashima et al, 2003). However, the present study did not show a correlation between the HGF/c-Met pathway and tumour vascularity in NSCLCs.

Previous clinical studies have reported that overexpression of HGF and/or c-Met is associated with the survival rate of patients with malignant tumours, including NSCLCs (Ichimura et al, 1996; Takanami et al, 1996; Siegfried et al, 1997), breast cancers (Edakuni et al, 2001), and thyroid cancers (Ramirez et al, 2000). However, few studies on NSCLCs have evaluated both HGF and cMet expression, and distinguished tumour cell derived-expression from stromal cell-derived expression. The present study demon- 
A

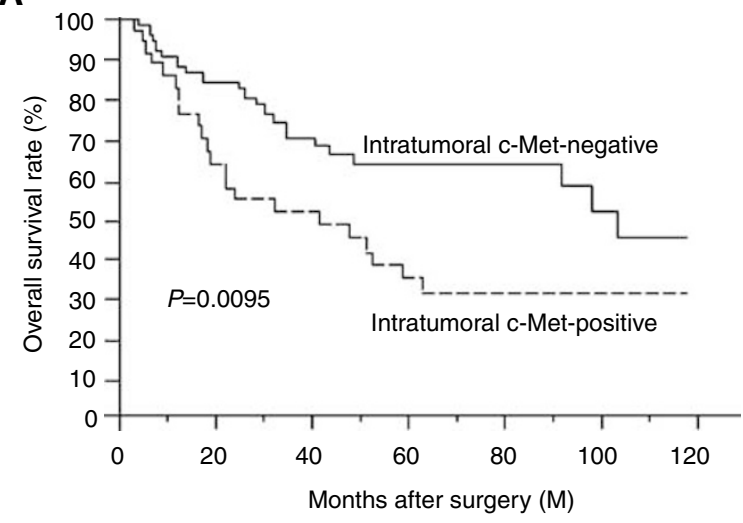

C

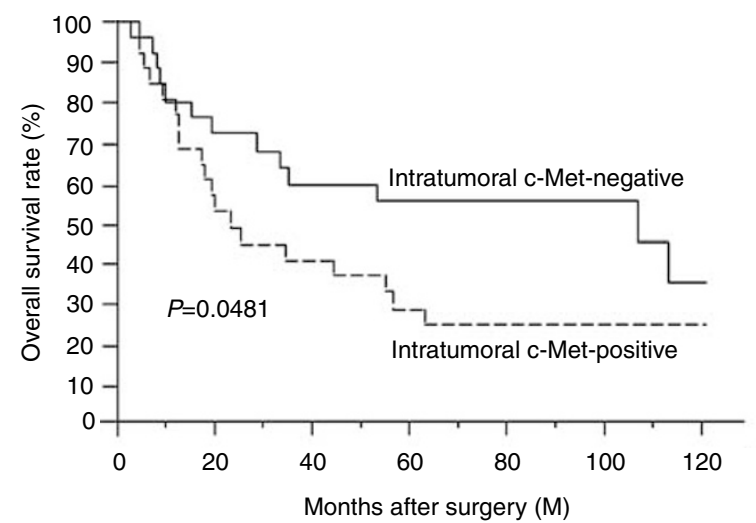

B

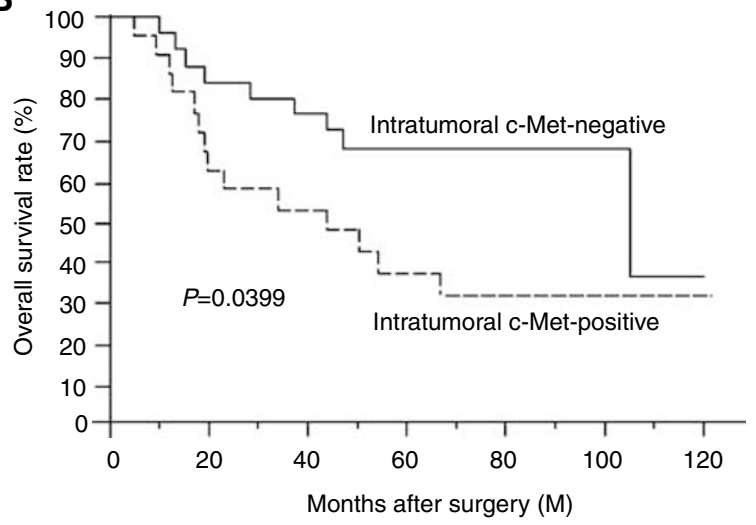

D

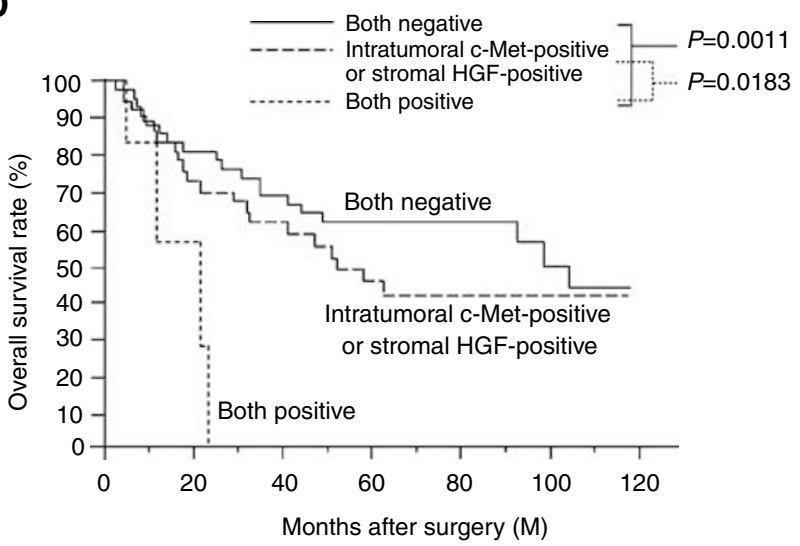

Figure 3 (A) Overall survival of 88 NSCLC patients in relation to intratumoral c-Met status. (B) Overall survival of 46 patients with adenocarcinomas in relation to intratumoral c-Met status. (C) Overall survival of 53 patients with T2-4 carcinomas in relation to intratumoral c-Met status. (D) Overall survival of 88 NSCLC patients in relation between stromal HGF and intratumoral c-Met status.

strates that the survival rate for patients with intratumoral c-Metpositive tumours is significantly lower than that of patients with intratumoral c-Met-negative tumours, and that the survival rate for patients with tumours with both positive expression of intratumoral c-Met and stromal HGF is significantly lower than that for patients with tumours with either positive expression, or with tumours with both negative expression. Although a multivariate analysis using intratumoral c-Met status and tumour status was not proper because of tumour status depending on intratumoral cMet expression, a univariate analysis using the Cox regression model demonstrated that intratumoral c-Met status had a significant effect on the prognosis of NSCLC patients. These results agreed with a previous clinical study on breast cancers (Edakuni et al, 2001).

\section{REFERENCES}

Bottaro DP, Rubin JS, Faletto DL, Chan AM-L, Kmiecik TE, Vande Wounde GF, Aaronson SA (1991) Identification of the hepatocyte growth factor receptor as the c-met prot-oncogene product. Science 251: 802-804

Brinkmann V, Foroutan H, Sachs M, Weidner KM, Birchmeier W (1995) Hepatocyte growth factor/scatter factor induces a variety of tissuespecific morphogenic programs in epithelial cells. J Cell Biol 131: 1573 1586

Bussolino F, Di Renzo MF, Ziche M, Bocchietto E, Olivero M, Naldini L, Gaudino G, Tamagnone L, Coffer A, Comoglio PM (1992) Hepatocyte growth factor is a potent angiogenic factor which stimulates endothelial cell motility and growth. J Cell Biol 119: 629-641
In conclusion, the present study on NSCLCs has demonstrated that intratumoral c-Met and stromal HGF expression promote tumour growth. Furthermore, intratumoral c-Met expression is a potent prognostic factor of NSCLC patients. A recent study reported that c-Met can also be activated by semaphoring $4 \mathrm{D}$ to trigger invasive cell growth (Giordano et al, 2002). Although further studies are necessary to clarify these mechanisms (Trusolino et al, 2001), these studies on the HGF/c-Met pathway will aid the development of new therapeutic strategies for the treatment of NSCLC cancer patients. For example, the HGF antagonist NK4 suppresses tumour growth and could improve the clinical outcome of patients with carcinomas that exhibit overexpression of HGF and/or c-Met (Date et al, 1998; Kuba et al, 2000).
Chung LW (1995) The role of stromal-epithelial interaction in normal and malignant growth. Cancer Surv 23: 33-42

Cordon-Cardo C (1995) Mutation of cell cycle regulators: biological and clinical implications for human neoplasia. Am J Pathol 147: 545-560

Date K, Matsumoto K, Kuba K, Shimura H, Tanaka M, Nakamura T (1998) Inhibition of tumor growth and invasion by a four-kringle antagonist (HGF/NK4) for hepatocyte growth factor. Oncogene 17: $3045-3054$

Edakuni G, Sasatomi E, Satoh T, Tokunaga O, Miyazaki K (2001) Expression of the hepatocyte growth factor/c-Met pathway is increased at the cancer front in breast carcinoma. Pathol Int 51: 172-178 
Folkman J (1990) What is the evidence that tumors are angiogenesis dependent? J Natl Cancer Inst 82: 4-6

Folkman J (1995) Angiogenesis in cancer, vascular, rheumatoid and other disease. Nat Med 1: 27-31

Gerde J, Lemke H, Baisch H, Wacker H, Schwab M, Stein H (1984) Cell cycle analysis of a cell-proliferation associated nuclear antigen defined by the monoclonal antibody Ki-67. J Immunol 133: 1710-1715

Giordano S, Corso S, Conrotto P, Artigianni S, Gilestro G, Barberis D, Tamagnone L, Comoglio PM (2002) The semaphorin 4D receptor controls invasive growth by coupling with Met. Nat Cell Biol 4: $720-724$

Ichimura E, Maeshima A, Nakajima T, Nakamura T (1996) Expression of cmet/HGF receptor in human non-small cell lung carcinomas in vitro and its prognostic significance. Jpn J Cancer Res 87: 1063-1069

Jin L, Fuchs A, Schnitt SJ, Yao Y, Joseph A, Lamszus K, Park M, Goldberg ID, Rosen EM (1997) Expression of scatter factor and c-met receptor in benign and malignant breast tissue. Cancer 79: 749-760

Kajita T, Ohta Y, Kimura K, Tamura M, Tanaka Y, Tsunezuka Y, Oda M, Sasaki T, Watanabe G (2001) The expression of vascular endothelial growth factor $\mathrm{C}$ and its receptors in non-small cell lung cancer. $\mathrm{Br} J$ Cancer 85: $255-260$

Kuba K, Matsumoto K, Date K, Shimura H, Tanaka M, Nakamura T (2000) HGF/NK4, a four-kringle antagonist of hepatocyte growth factor, is an angiogenesis inhibitor that suppresses tumor growth and metastasis in mice. Cancer Res 60: 6737-6743

Kurimoto S, Moriyama N, Horie S, Sakai M, Kameyama S, Akimoto Y, Hirano H, Kawabe K (1998) Co-expression of hepatocyte growth factor and its receptor in human prostate cancer. Histochem J 30: 27 - 32

Masuya D, Huang C, Liu D, Kameyama K, Hayashi E, Yamauchi A, Kobayashi S, Haba R, Yokomise H (2001) The intratumoral expression of vascular endothelial growth factor and interleukin-8 associated with angiogenesis in nonsmall cell lung carcinoma patients. Cancer 92: $2628-2638$

Matsuyama K, Chiba Y, Sasaki M, Tanaka H, Muraoka R, Tanigawa N (1998) Tumor angiogenesis as a prognostic marker in operable nonsmall cell lung cancer. Ann Thorac Surg 65: 1405-1409

Montesano R, Matsumoto K, Nakamura T, Orci L (1991) Identification of fibroblast-derived epithelial morphogen as hepatocyte growth factor. Cell 61: $901-908$

Mountain CF (1997) Revisions in the international system for staging lung cancer. Chest 111: $1710-1717$

Nakamura T, Matsumoto K, Kiritoshi A, Tano Y, Nakamura T (1997) Induction of hepatocyte growth factor in fibroblasts by tumor-derived factors affects invasive growth of tumor cells: in vitro analysis of tumor stromal interactions. Cancer Res 57: 3305-3313

Nakamura T, Nishizawa T, Hagiya M, Seki T, Shimonishi M, Sugimura A, Tashiro K, Shimizu S (1989) Molecular cloning and expression of human hepatocyte growth factor. Nature 342: $440-443$
Nakashima T, Huang C, Liu D, Kameyama K, Masuya D, Kobayashi S, Kinoshita M, Yokomise H (2003) Neural-cadherin expression associated with angiogenesis in non-small-cell lung cancer patients. Br J Cancer 88: $1727-1733$

Olivero M, Rizzo M, Madeddu R, Casadio C, Pennacchietti S, Nicotra MR, Prat M, Maggi G, Arena N, Natali PG, Comoglio PM, Di Renzo MF (1996) Overexpression and activation of hepatocyte growth factor/scatter factor in human non-small-cell lung carcinomas. Br J Cancer 74: 1862-1868

Park M, Dean M, Kaul K, raun MJ, onda MA, Vande Wounde G (1987) Sequence of MET proto-oncogene cDNA has features characteristic of the tyrosine kinase family of growth-factor receptors. Proc Natl Acad Sci USA 84: $6379-6383$

Ramirez R, Hsu D, Patel A, Fenton C, Dinauer C, Tuttle RM, Francis GL (2000) Over-expression of hepatocyte growth factor/scatter factor (HGF/ $\mathrm{SF}$ ) and the HGF/SF receptor (cMET) are associated with a high risk of metastasis and recurrence for children and young adults with papillary thyroid carcinoma. Clin Endocrinol 53: 635-644

Scagliotti GV, Micela M, Gubetta L, Leonardo E, Cappia S, Borasio P, Pozz E (1993) Prognostic significance of Ki67 labelling in resected non small cell lung cancer. Eur J Cancer 29A: $363-365$

Siegfried JM, Weissfeld LA, Singh-Kaw P, Weyant RJ, Testa JR, Landreneau RJ (1997) Association of immunoreactive hepatocyte growth factor with poor survival in resectable non-small cell cancer. Cancer Res 57: 433 - 439

Takanami I, Tanana F, Hashizume T, Kikuchi K, Yamamoto Y, Yamamoto T, Kodaira S (1996) Hepatocyte growth factor and c-Met/hepatocyte growth factor receptor in pulmonary adenocarcinomas: an evaluation of their expression as prognostic markers. Oncology 53: 392-397

Tamura M, Arakaki N, Tsubouchi H, Takeda H, Daikuhara Y (1993) Enhancement of human hepatocyte growth factor production by interleukin- $1 \alpha$ and $-\beta$ and tumor necrosis factor- $\alpha$ by fibroblast in culture. J Biol Chem 268: $8140-8145$

Trusolino L, Bertotti A, Comoglio PM (2001) A signaling adapter function for $\alpha 6 \beta 4$ integrin in the control of HGF-dependent invasive growth. Cell 107: $643-654$

Turkeri LN, Erton ML, Cevik I, Akdas A (1998) Impact of the expression of epidermal growth factor, transforming growth factor alpha, and epidermal growth factor receptor on the prognosis of superficial bladder cancer. Urology 51: 645-649

Webb CP, Taylor GA, Jeffers M, Fiscella M, Oskarsson M, Resau JH, Vande Wounde GF (1998) Evidence for a role of Met-HGF/SF during Rasmediated tumorigenesis/metastasis. Oncogene 17: 2019-2025

Weidner KM, Arakaki N, Hartmann G, Vandekerckhove J, Weingart S, Rieder H, Fonatsch C, Tsubouchi H, Hishida T, Daikuhara Y, Birchmeier W (1991) Evidence for the identity of human scatter factor and human hepatocyte growth factor. Proc Natl Acad Sci USA 88: 7001-7005

Weidner KM, Behrens J, Vandekerckhove J, Birchmeier W (1990) Scatter factor: molecular characteristics and effect of the invasiveness of epithelial cells. J Cell Biol 111: $2097-2108$ 